\title{
Diagnostic and Analysis of Specific Soil with Ground Water Level and Plain Concrete Slab Interaction
}

\author{
Oldrich SUCHARDA ${ }^{1}$, Radim CAJKA ${ }^{2}$, Zuzana MARCALIKOVA ${ }^{2}$, Lubos PAZDERA ${ }^{3}$ \\ and Vlastimil BILEK ${ }^{1}$
}

Authors' affiliations and addresses:

${ }^{1}$ Department of Materials and Diagnostics of Structures, Faculty of Civil Engineering, VSBTechnical University of Ostrava, Ludvíka Podéště 1875/17, 708 00, Ostrava-Poruba, Czech

Republic

e-mail: oldrich.sucharda@vsb.cz

e-mail: vlastimil.bilek@vsb.cz

${ }^{2}$ Department of Structures, Faculty of Civil Engineering, VSB-Technical University of Ostrava, Ludvíka Podéště 1875/17, 708 00, Ostrava-Poruba, Czech Republic

e-mail: radim.cajka@vsb.cz

e-mail: zuzana.marcalikova@vsb.cz

${ }^{3}$ Institute of Physics, Faculty of Civil

Engineering, Technical University of Brno, Veveří 331/95, 60200 Brno, Czech Republic e-mail: pazdera.1@fce.vutbr.cz

*Correspondence:

Zuzana Marcalikova, Department of Structures, Faculty of Civil Engineering, VSB-Technical University of Ostrava, Ludvíka Podéště 1875/17, 708 00, Ostrava-Poruba, Czech Republic; tel.: +420597321382

e-mail: zuzana.marcalikova@vsb.cz

Funding information:

Ministry of Education, Youth and Sports of the Czech Republic.

\section{Acknowledgement:}

The work was supported by the means of conceptual development of science, research and innovation assigned to VŠB-TUO by the Ministry of Education, Youth and Sports of the Czech Republic.

How to cite this article:

Sucharda, O., Cajka, R., Marcalikova, Z., Pazdera, L. and Bilek, V. (2020). Diagnostic and Analysis of Specific Soil with Ground Water Level and Plain Concrete Slab Interaction. Acta Montanistica Slovaca, Volume 25 (3), 427-443

DOI:

https://doi.org/10.46544/AMS.v25i3.14

\begin{abstract}
This article deals with the selected task soil and structure interaction in case of a thin concrete slab and increased groundwater level. The soil and structure interaction is a complex task applied in cases when necessary to sufficiently consider the proposal's safety and economy. The particular topic dealt with is the performed specific experiment of a concrete slab on the subsoil that is subsequently simulated using 3D computing models. The performed experiment is a concrete slab with dimensions $2000 \times 2000 \mathrm{~mm}$. The concrete slab thickness was $150 \mathrm{~mm}$. Computing models are based on the Finite Element Method and non-linear analyses. The specificity of the experiment is that it simulates extreme foundation conditions when the groundwater level almost reaches the foundation base. The experiment confirmed the significant effect of the groundwater level, the reduction of the overall bearing capacity of the slab and the rapid disturbance and collapse of the slab. Numerical models also described very well the occurrence of cracks and slab collapse. The results were in good agreement with the experimental testing. Major specificities include that the measuring and load test records are supplemented with an acoustic emission to identify concrete cracks. Findings from acoustic emission make it possible to describe the formation of cracks at a time when cracks are not visible and to verify the subsequent behaviour of the slab. The research task presented also includes detail laboratory tests of the concrete used. Laboratory tests include tests of compressive strength, modulus of elasticity and tensile strength. Tensile strength was determined based on splitting tensile strength and bending tensile strength tests. In the case of bending tensile strength, test variants were performed, which differed in the test configuration (three-point bending test, four-point bending test), the size of the test specimens and the notch in the middle of their span. Numerical modelling of the slab's interaction with the subsoil is also preceded by modelling a small structural element, a beam with reinforcement. Numerical modelling itself is also based on the use of the concept identification of fracture mechanics parameters by laboratory tests.
\end{abstract}

\section{Keywords}

soil; acoustic emission; structure; concrete; fracture parameters; interaction; concrete, numerical model; non-linear analysis 


\section{Introduction}

The design of building structures includes many technical, architectural and functional criteria. The task dealt with is part of the design of foundation structures where the basic criteria include a layout of the upper structure, supporting system, operating and technical conditions, load volume and foundation conditions. The most frequent types of foundation structures include shallow foundations. Typical specific problems of these types of foundations include foundations in the undermined area, horizontal load, seismic effects (Kaláb and Štemon, P., 2017) or vibrations (Ceylanoğlu and Gül, 2016; Kaláb and Hrubešová, E., 2015). With respect to the realisation of the structure or extreme weather conditions, it is possible to experience a case of increased groundwater level. This may significantly influence safety. The area in question deals with this problem. An important aspect for the design and modelling of the foundation slab interaction with the subsoil is that it connects the structural design and geotechnics area. Design and analysis of the concrete structure in interaction with the subsoil is a complex research area, for example, punching of concrete footings (Hegger, Ricker, Ulke and Ziegler, 2006) and (Hegger, Sherif and Ricker, 2006), structural behaviour and deformation of groundsupported concrete slabs (Aboutalebi, Alani, Rizzuto and Beckett, 2014) or punching shear of flat slabs (Ricker and Siburg, 2016). This problem is illustrated in Fig. 1 and is often referred to as SSI (Soil-Structure Interaction).

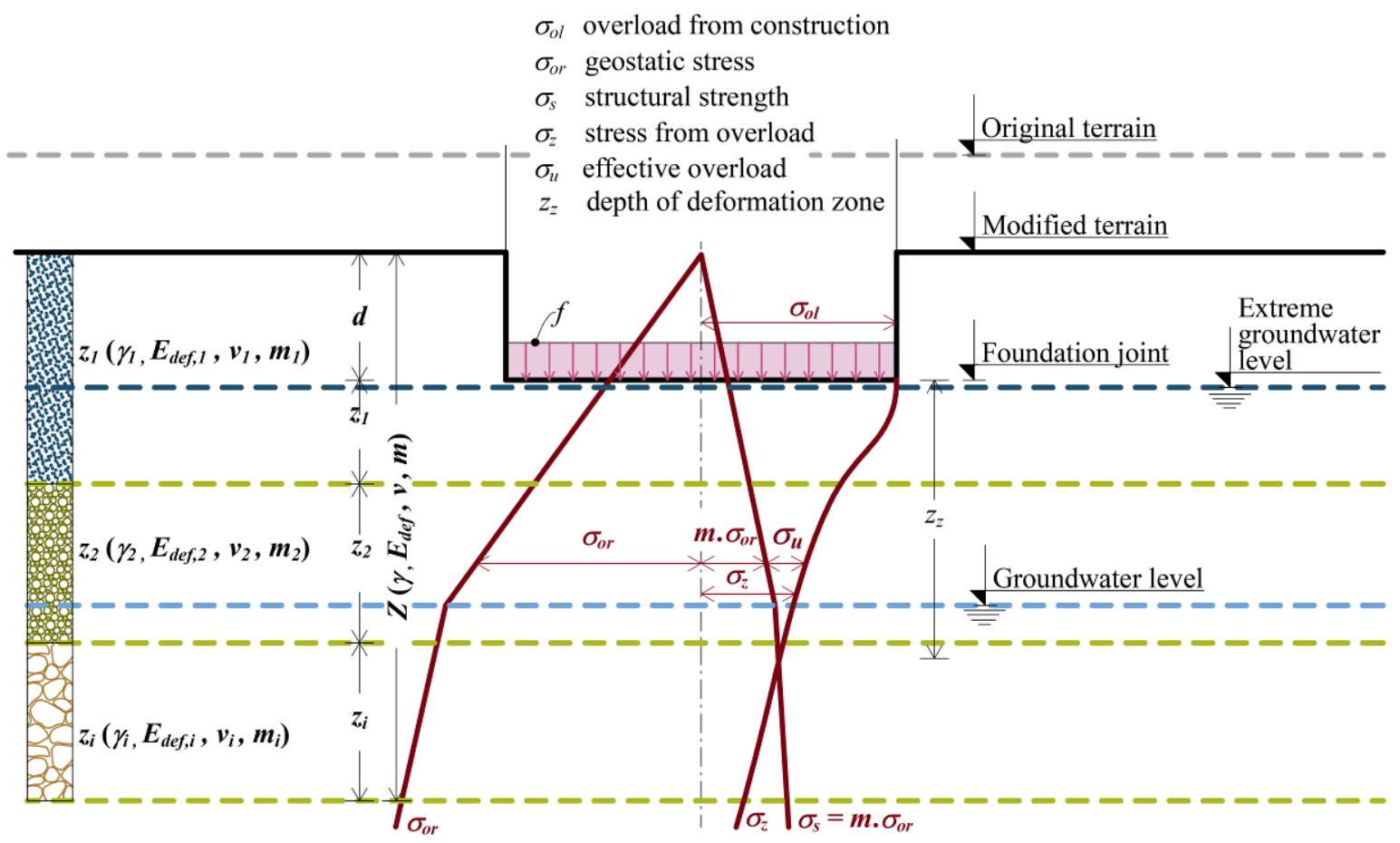

Fig. 1. Problems of the construction task of the interaction of the slab with the subsoil

There is an impact of interaction and load redistribution within the global structure system. In case of the task dealt with, it is important that a load of supporting structural elements would change the subsoil's stress condition. This subsequently results in deformations and secondary forces in the supporting structure of the upper structure. This applies in particular in case of different contact stress in the foundation base. Typically, this may occur in industrial floors. This focus has a great deal of attention in the research in the world in the area of shear reinforcement for footings (Kueres, Ricker and Hegger, 2018), of stiffness analysis of the subsoil under the industrial floor (Tomasovicova and Jendzelovsky, 2017), of contact problem (Kralik and Jendzelovsky, 1994), punching behaviour (Siburg and Hegger, 2014), of modelling of soil-structure interaction (Kolář and Němec, 1989). The analysis is also often solved with the seismic problem. For this task, an influence of physical, geometric and structural nonlinearity is also typical. This is particularly the case when the construction collapse and total bearing capacity are monitored. For these reasons, it is important to make research of experiments of concrete slab und numerical models (Cajka et al., 2016), (Cajka, Krivy and Sekanina, 2011), maximum punching shear resistance of flat slabs (Halvonik and Fillo, 2013), improved shear reinforcement for footings (Kueres, Ricker and Hegger, 2017), research with punching shear capacity (Hoang and Pop, 2016) and eccentric load (Cajka et al., 2019). The typical experiment of concrete and fibre reinforced concrete slab with subsoil were performed (Cajka et al., 2020, Cajka, Krivy and Sekanina, 2011). The specialised test equipment and slab used can be seen in Figs. 2 and 3. 


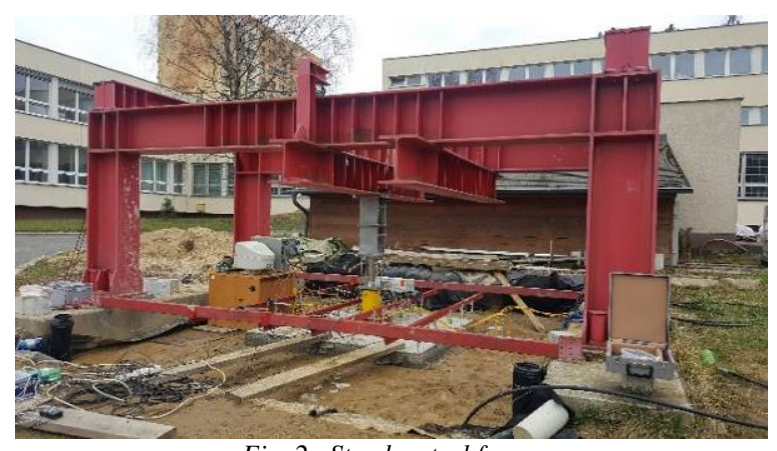

Fig. 2. Stend-steel frame

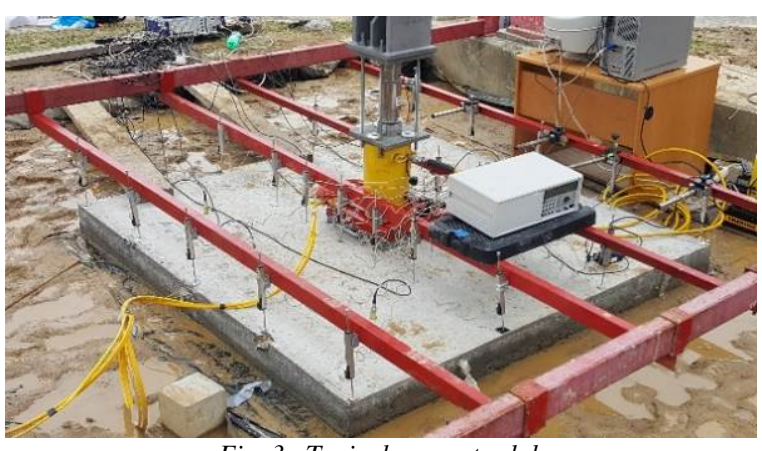

Fig. 3. Typical concrete slab

Main aspects in the solution of the task of the interaction of the foundation with the subsoil can be classified on the detail of the geometry of the modelled foundation structure and subsoil, constitutive relations for material models (modulus of elasticity, the strength of subsoil, volume weight, thermal expansion), impact and interface of separated layers (concrete/soil, friction, contact) and subsoil model (multilayer, elastic half-space model, finite element method). For the overall building and structural solution of building foundations, it is appropriate to proceed from standard suggestions that typically include non-freezing (frosty) depth, groundwater level, and contact stress.

Design models of concrete slabs and geotechnical tasks are typically used (EN 1997-1, 2004) and (CSN EN 1992-1-1, 2006). To achieve comprehensible numerical results, the core of the problem is to be understood. There are a number of design and numerical methods to solve the task of the interacting slab with the subsoil. Typical cases include the use of analytical methods that often significantly simplify the solution. On the other hand, it is possible to use the finite element method (Zienkiewicz, 1971). There are, however, specialised methods for specific tasks, when it is also possible to find a solution for combined and advanced analysis combining numerical and special measurements (Sokol et al., 2020). With the finite element method, it is possible to take into account the non-linear behaviour of the problem solved. In this method and task, a whole range of options and parameterisation of the computational model was created.

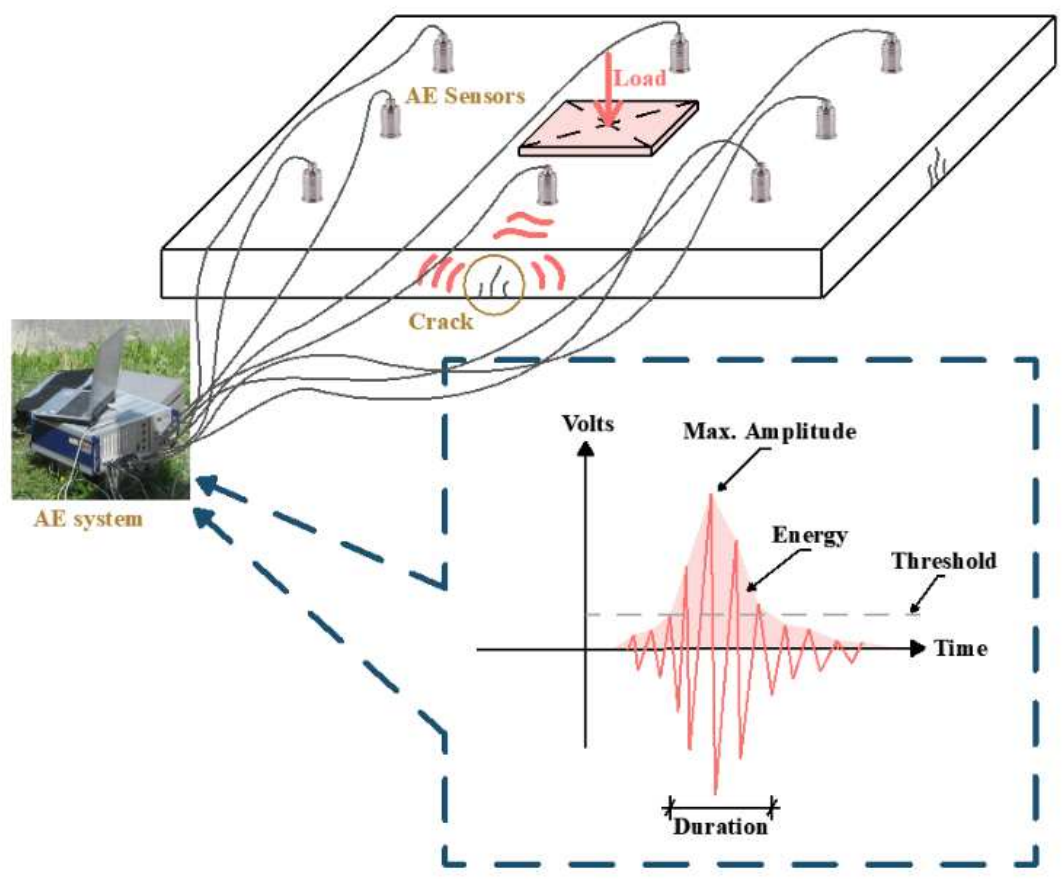

Fig. 4. Measurement concept AE of a typical concrete slab

The computational model is based on discretising finite elements and material models. Some approaches using advanced methods and calculations are shown in (Sucharda, 2020), (Sucharda and Konecny, 2018), (Cajka, 2013), (Sucharda et al., 2018) and (Ibrahim and Metwally, 2014). This article aims to this research area. Numerical modelling of building structures is based on creating a computing model, which, using the mathematical formulation, will express sufficiently actual behaviour of the structure. Computing models can be classified in particular with respect to the task dimension. The task dealt with is resolved using a 3D model. In 
case of the solution for interaction of the foundations and subsoil, it is suitable to take into account the boundary conditions and the size of the simulated subsoil with respect to dimensions and the load applied. The use of numerical modelling based on the method of finite elements and non-linear analysis requires detailed knowledge of the behaviour (concrete destruction) and record from experiments to validate fidelity.

For this reason, an acoustic emission (AE) (Grosse and Ohtsu, 2008), (Pollock, 1988) was used for detail and better identification of material destruction, and it was also used in selected cases for the concrete (Sagasta et al., 2016), (Topolar et al., 2017), (Pazdera and Topolar, 2014) and (Lacidogna, Piana and Carpinteri, 2017). The selected measurement concept AE is shown in Fig. 4. AE application is used as a control element of material destruction or in the optimisation of technologies (Nosov, 2016) or monitored historical structures (Invernizzi, Lacidogna and Carpinteri, 2016). However, with respect to the research already made, there is still a broad area remaining for new application methods of the acoustic emission. One of these options for concrete structures is presented in the article (Pazdera et al., 2019), when the occurrence of cracks at the lower surface may significantly influence the service life of the structure. An inspection and direct verification of this occurrence are very difficult in the task dealt with.

\section{Non-linear analysis}

\section{Material and Methods}

The use of non-linear analysis is currently typically part of innovative design solutions and computer simulations of the non-linear behaviour of structures, where this approach makes it possible to take into account real behaviour in structural design and analysis. Summary results of the research and a number of recommendations on concrete and concrete structures can be found in Model Code 2010 (Model Code 2010 Final draft). On this basis, there are several possibilities for the use of material models - Disturbed stress field model for reinforced concrete, Microplane Model or Fracture-plastic material model (Cervenka and Papanikolaou, 2008), (Cervenka, Jendele and Cervenka, 2016) for non-linear analysis. However, the actual material models differ in terms of accuracy, computational difficulty, range of tasks, and quality of results. Remodelling can also be used for laboratory tests of concrete (Brozovsky et al., 2009).

The use of non-linear analysis and material models is linked to the finite element method, which is based on the discretisation of the computational model in a small area, where a solution is then sought. The finite element method option selected by the authors is based on an equation expressing equilibrium conditions for the finite element:

$$
\mathbf{K u}=\mathbf{F}
$$

From the individual stiffness values of the finite elements $\mathbf{K}$, vectors of unknown deformations of the finite element $\mathbf{u}$ and the load vector of the finite element $\mathbf{F}$ a solution is compiled for the entire computational model. In the case of non-linear analysis and finite element method calculation, the stiffness matrix of the structure is recorded as:

$$
\mathbf{K}=\mathbf{K}(\mathbf{u})
$$

The original system of linear equations becomes non-linear. The system of non-linear equations is solved incrementally, linearising the properties for a given iteration:

$$
\Delta \boldsymbol{\sigma}=\mathbf{D}_{p} \Delta \boldsymbol{\varepsilon}
$$

where $\Delta \sigma$ is the stress increment vector, $\Delta \varepsilon$ is the relative elongation increment vector, and $\mathbf{D}_{\mathbf{p}}$ is the material stiffness matrix for a given iteration interval.

\section{Composition of concrete and subsoil}

Among the specifics of the experiment are elevated groundwater level and the subsoil change, as shown in Figs. 5 and 6. Before compaction, the soil used had an incoherent soil composite nature (about 55\% sand, 15\% gravel) and clay lenses accounted for the remaining ca. $30 \%$. However, during the backfill and compaction, there was a significant decomposition and mixing with the rest of the soil volume. According to the percentage of individual fractions, this soil can be globally classified as clayey sand SC (S5)/loamy sand SM (S4). 


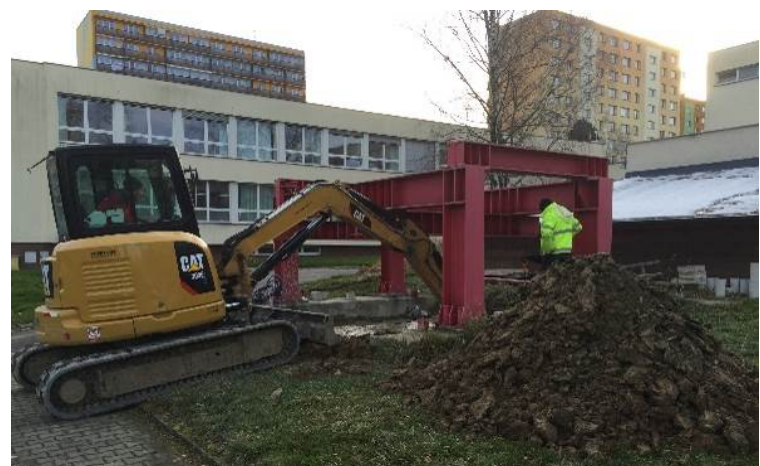

Fig. 5. Subsoil replacement

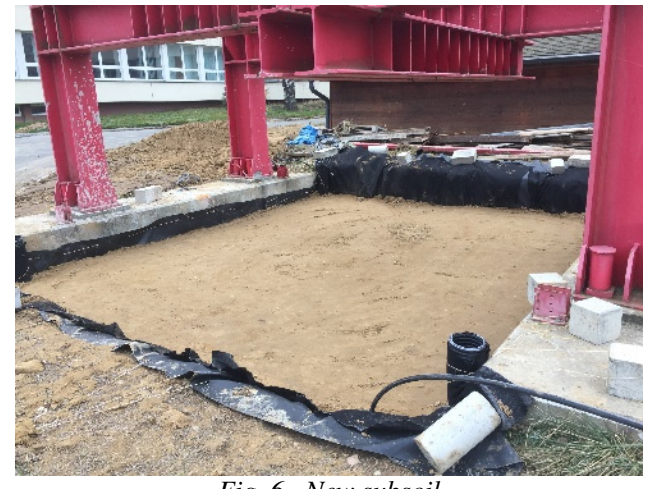

Fig. 6. New subsoil

The initial composition of the concrete mixture for the slab is shown in Tab. 1. The concrete is normal concrete intended for structural purposes (e.g. foundations, floors). The maximum grain size of the concrete mix was $16 \mathrm{~mm}$, and the water coefficient was 0.6. Portland fast setting cement $42.5 \mathrm{MPa}$ was used for the concrete. The concrete also contains Stacheplast plasticising agent. It was a transport concrete.

\begin{tabular}{cc} 
Tab. 1. Material composition, properties of the concrete mixture \\
\cline { 2 - 2 } Material composition & Values \\
\hline Consistency & $\mathrm{S} 3$ \\
CEM & I $42.5 \mathrm{R}$ \\
Minimum content of cement & $300 \mathrm{~kg}$ \\
Water-cement ratio: $w / c$ & 0.6 \\
Aggregates $0 / 4$ & $870 \mathrm{~kg}$ \\
Aggregates 4/8 & $150 \mathrm{~kg}$ \\
Aggregates $8 / 16$ & $820 \mathrm{~kg}$ \\
Water & 1891 \\
Plasticiser & 2.91 \\
\hline
\end{tabular}

\section{The experiment of setup and diagnostic of the concrete slab}

The main part of the research was the load test of the concrete slab on the subsoil. VSB - Technical University of Ostrava, Faculty of Civil Engineering (Cajka, Krivy and Sekanina, 2011) has a special equipment/device for this purpose. This equipment has a test frame with a hydraulic press with the capacity of $1000 \mathrm{kN}$. Since 2018, new parts of the equipment and accessories include a hermetically sealed subsoil area to monitor and regulate groundwater level. The sealed subsoil area is formed by the waterproofing membrane system and drainage system with four pipes regulating groundwater. The depth of the waterproofing basin is $1.05 \mathrm{~m}$, and it spreads around the steel structure. Its segments can be seen in Fig. 7. This test equipment/device is connected to a universal measurement panel for deformation, strain and force. Deformation measuring points are apparent from the diagram in Fig. 8.
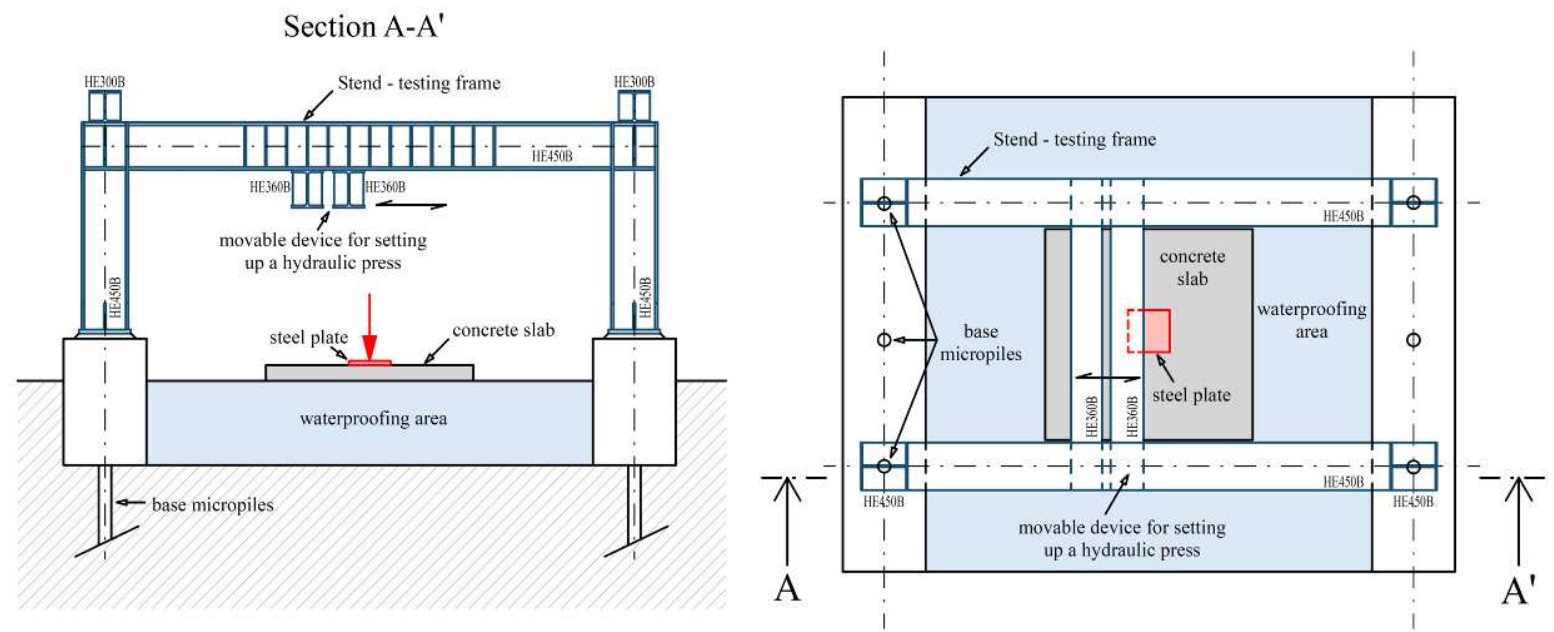

Fig. 7. Stend-testing frame: scheme 


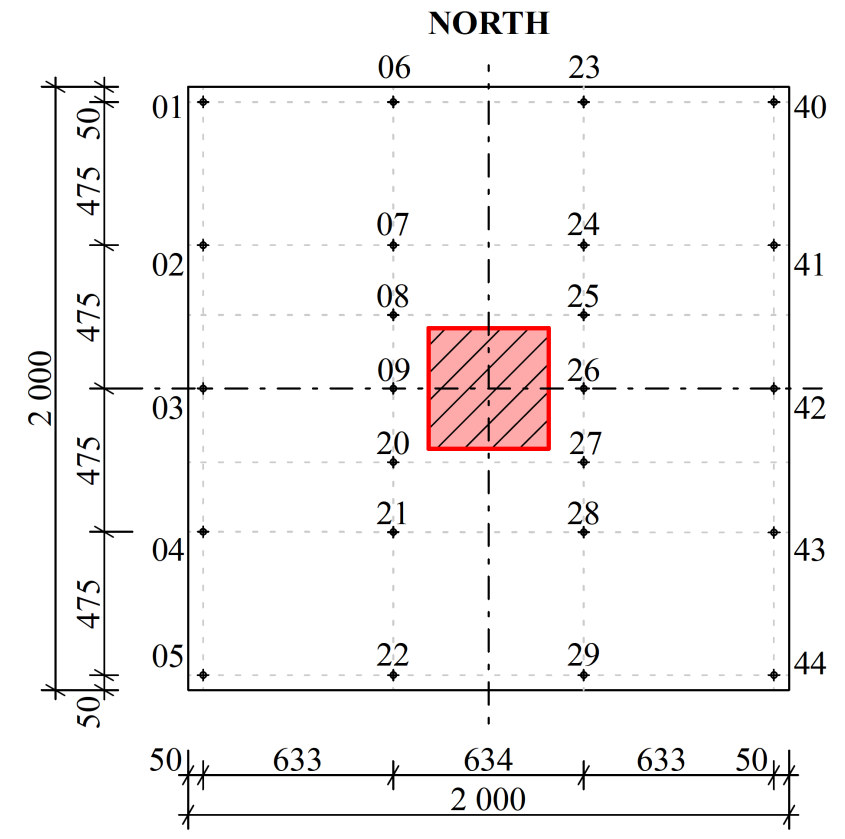

Fig. 8. Scheme of the concrete slab and measuring deformations

The concrete slab has dimensions up to 2000 x $2000 \mathrm{~mm}$ and a thickness of $150 \mathrm{~mm}$. Typical tested concrete slab during the test is shown in Fig. 9. The subsoil has typical $E_{\text {soil }}$ values of 3 to $53 \mathrm{MPa}$. For the experiment carried on, extreme conditions with $E_{\text {soil }}=1.5 \mathrm{MPa}$ were however chosen. The groundwater level reached the level of the foundation base. Part of the modification of the experimental testing equipment was subsoil replacement.

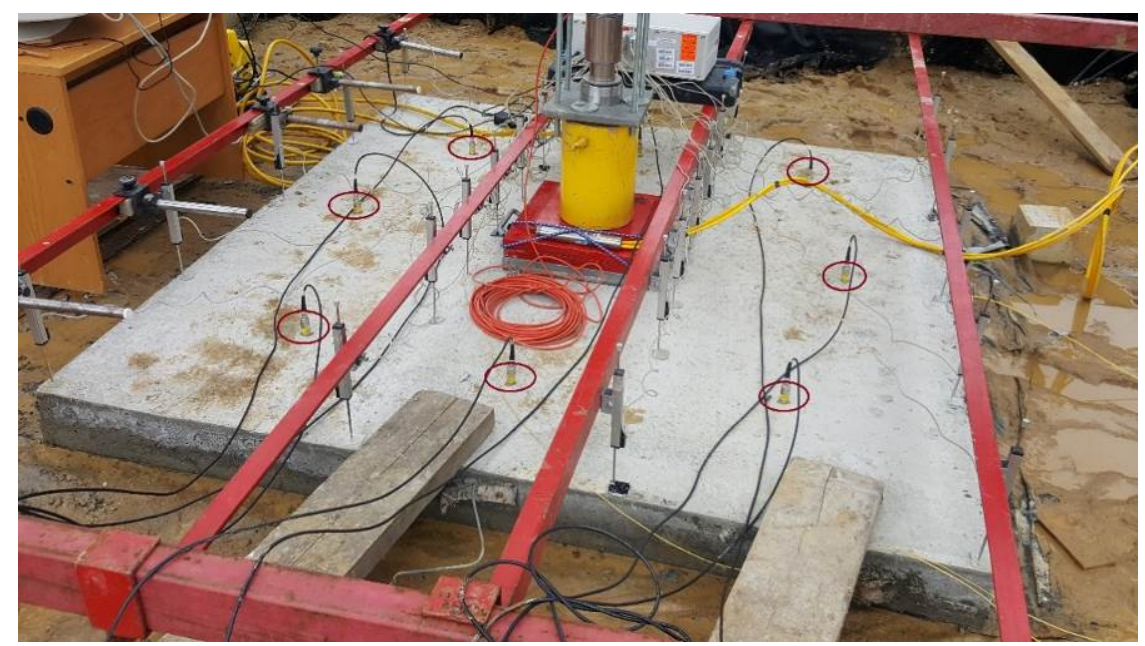

Fig. 9. Concrete slab-during the test: AE sensors

The slab is equipped with sensors for measuring the deformation and eighth acoustic sensors, see Fig. 9. The acoustics sensors were of the type MTPA-15, with an integrated $35 \mathrm{~dB}$ pre-amplifier (type) attached to the surface of the sample with beeswax. The DAKEL-XEDOC universal measuring and diagnostic system developed by ZD Rpety-Dakel was used to process and record AF signals. The XEDO-AE unit used for the assessment of acoustic emission parameters. When connected to an acoustic emission sensor, it allows measurement of standard AE parameters, processing of emission occurrences together with their localisation and direct digital sampling.

\section{Laboratory test of setup and concrete properties}

The basic laboratory program of the concrete properties included nine variants, which included the compressive strength of cube $(150 \mathrm{~mm} \times 150 \mathrm{~mm} \times 150 \mathrm{~mm})$, the compressive strength of cylinder $(150 \mathrm{~mm} \times$ $300 \mathrm{~mm})$, split tensile strength $(150 \mathrm{~mm} \times 150 \mathrm{~mm} \times 150 \mathrm{~mm})$, three-point and four-point bending tests. For 
determining the mechanical properties of concrete and fibre concrete, there are several options, which are summarised (Marcalikova et al., 2020).

The compressive strength (ČSN ISO 1920-4 Testing of concrete - Part 4: Strength of hardened concrete) of the concrete in Fig. 10 was tested on 150 x 150 x $150 \mathrm{~mm}$ cubes, or cylinders $150 \mathrm{~mm}$ in diameter and $300 \mathrm{~mm}$ in height.

The cylinders were also used to test the modulus of elasticity of concrete, which is based on the evaluation of the difference of deformations for different load intensities. The very procedure for testing the static modulus show (ČSN ISO 1920-10 Testing of concrete - Part 10: Determination of static modulus of elasticity in compression).

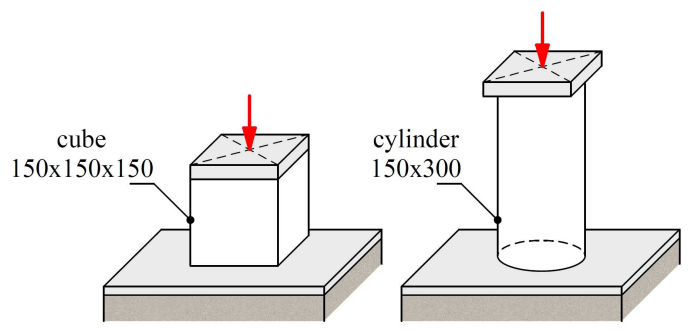

Fig. 10. Testing compressive strength and modulus of elasticity

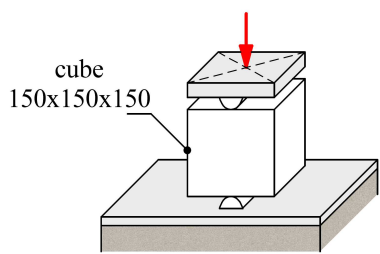

Fig. 11. Splitting tensile strength testing

In addition, splitting tensile strength tests were performed; the test configuration is shown in Fig. 11. Other tests included the three most common variants of the three-point bending test shown in Fig. 12. The tests differ in the span and notch, which determines the localisation of the crack. The test marked 3B600 is for a beam of nominal size of $150 \times 150 \times 700 \mathrm{~mm}$, a span of $600 \mathrm{~mm}$, and the cross-section has a notch height of $50 \mathrm{~mm}$. The second option, marked 3B500, is for a beam of a nominal size of $150 \times 150 \times 600 \mathrm{~mm}$ and a span of $500 \mathrm{~mm}$. The third option, marked 3B500_25, is for a beam of nominal size $150 \times 150 \times 600 \mathrm{~mm}$, the span of $500 \mathrm{~mm}$ and a notch height of $25 \mathrm{~mm}$.
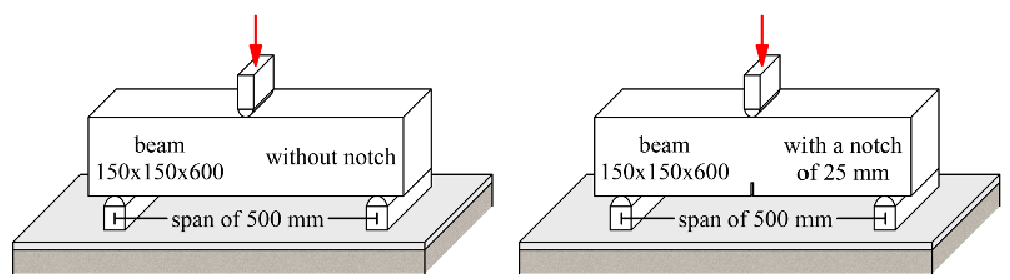

Fig. 12. Three-point bending test

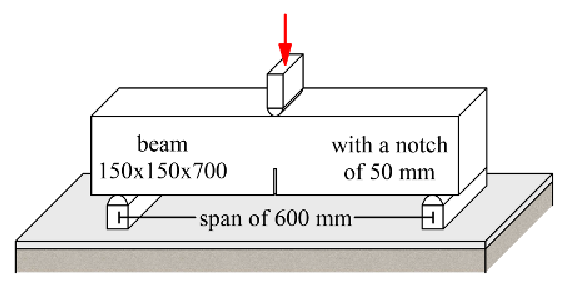

The last group of tests was four-point bending tests. Two selected variants 4B600 and 4B500 are shown in Fig. 13. The test marked 4B600, is for a beam of a nominal size of $150 \times 150 \times 700 \mathrm{~mm}$ and a span of $600 \mathrm{~mm}$. The distance between supports and forces is $200 \mathrm{~mm}$. The second option of the four-point bending test, marked 4B500, is for a beam of a nominal size of $150 \times 150 \times 600 \mathrm{~mm}$ and a span of $500 \mathrm{~mm}$.
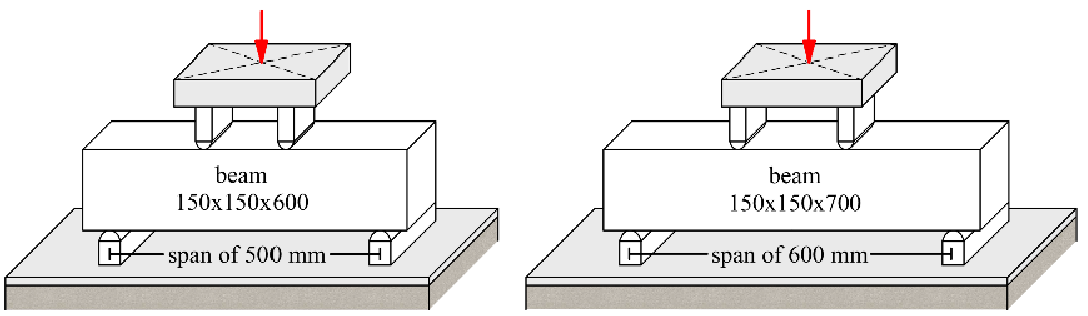

Fig. 13. Four-point bending test

For numerical modelling, however, it is necessary to know the strength of the concrete in uniaxial tension. For this reason, the tests were converted using known relationships (Sucharda et al., 2020), which are verified on a large number of experiments.

The laboratory test program also involved small structure elements - beam. The test beam is part of the multi-level identification of fracture mechanical composite parameters for advanced non-linear analysis of concrete and composite structures. Specifically, the beam was tested in a three-point bending test during the 
research. The beam has a rectangular cross-section of 100 x $190 \mathrm{~mm}$ and a typical span of $900 \mathrm{~mm}$. The diagram of the three-point bending test is shown in Fig. 14.

The beam was reinforced by two cross-sections of the B500B concrete reinforcement (10 mm diameter) at the bottom edge. The reinforcement cover was $20 \mathrm{~mm}$. The agreed yield strength of the steel was $500 \mathrm{MPa}$. The laboratory tests objective was to evaluate the load diagram during loading, which can subsequently be used for the identification and verification of fracture-mechanical concrete parameters. Vertical deflection of the beams was measured in the middle of the span at the lower surface by means of the extensometers. The beam was loaded with a deformation load.

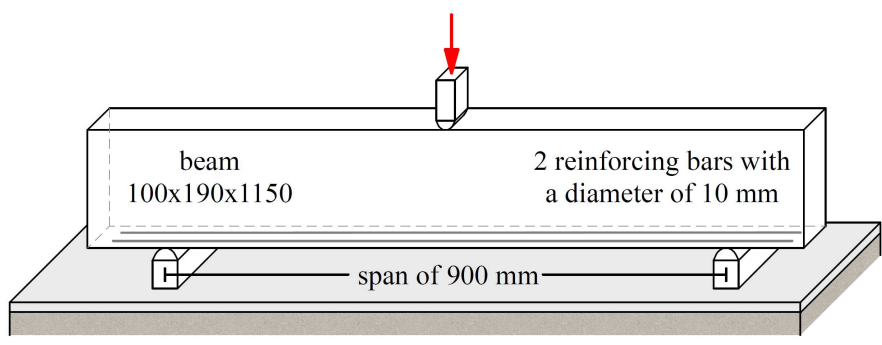

Fig. 14. Three-point bending test with RC beam

\section{Results}

\section{Material properties of concrete}

The overall mechanical properties of concrete are shown in Tab. 2. For a better idea of the potential variation of concrete's tensile strength, the data on the class used is added. The tensile strength itself was determined based on various tests. The individual results according to the test type are shown Fig. 15. The lowest values were obtained for the TB600_50 - three-point test for a $600 \mathrm{~mm}$ span with a $50 \mathrm{~mm}$ notch. The resulting tensile strength was achieved by TB500_25 - a three-point test for a $500 \mathrm{~mm}$ span with a $25 \mathrm{~mm}$ slit. Highest values were achieved with the CB500 - a four-point test for a $500 \mathrm{~mm}$ span. The value from the splitting tensile test was $2.21 \mathrm{MPa}$. The resulting tensile strength, taking into account the number of samples, was 2.12 $\mathrm{MPa}$.

\begin{tabular}{cccccccc}
\hline \multicolumn{1}{c}{ Tab. 2. Basic material properties } \\
& $f_{\mathbf{c}}$ & $f_{\text {c,cube }}$ & $\boldsymbol{E}$ & $f_{\text {ct, mean }}$ & $f_{\text {ctk,0,05 }}$ & $f_{\text {ctm }}$ & $f_{\text {ctk,0,95 }}$ \\
\cline { 2 - 8 } & {$[\mathrm{MPa}]$} & {$[\mathrm{MPa}]$} & {$[\mathrm{GPa}]$} & {$[\mathrm{MPa}]$} & {$[\mathrm{MPa}]$} & {$[\mathrm{MPa}]$} & {$[\mathrm{MPa}]$} \\
Samples & 6 & 6 & 3 & 20 & - & - & - \\
Size & 24.66 & 26.59 & 18.50 & 2.12 & 1.8 & 2.6 & 3.3 \\
\hline
\end{tabular}

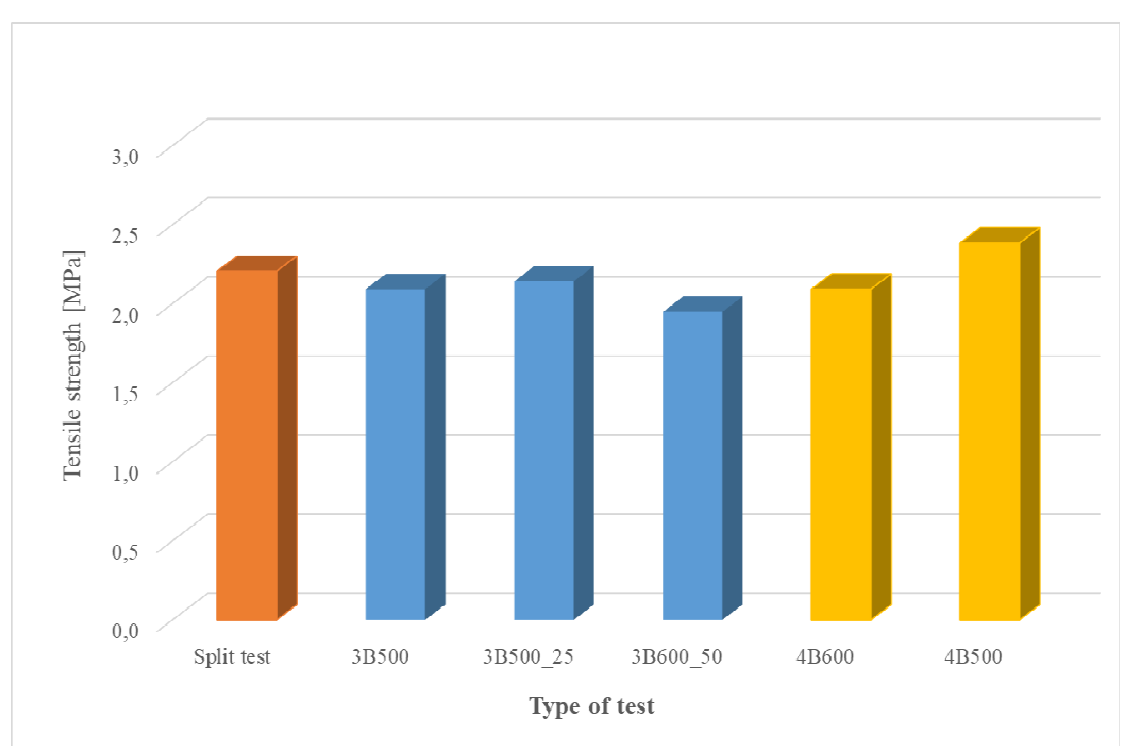

Fig. 15. Tensile strength of concrete [MPa] 


\section{Small structure element - experiment and model}

The very aim of numerical modelling was to determine the total bearing capacity and the manner of disruption. Numerical modelling was carried out using 2D computational models, namely the fracture-plastic concrete model, which is used in the ATENA system (Cervenka, Jendele and Cervenka, 2016). The 2D model includes a concrete beam, a reinforcement, a steel load plate and support. The calculation was based on recommendations and models (Sucharda and Konecny, 2018). The Newton-Raphson method was used for the non-linear solution of the task. The load was input by deformation. The basic input material characteristics of concrete used were taken from laboratory tests. Determining fracture energy was based on the ATENA manual recommendations when the calculation was performed using stochastic modelling (Sucharda, 2020).

The actual evaluation of the experimental loading test and the result of the follow-up non-linear analysis are shown in a graph in Fig. 16.

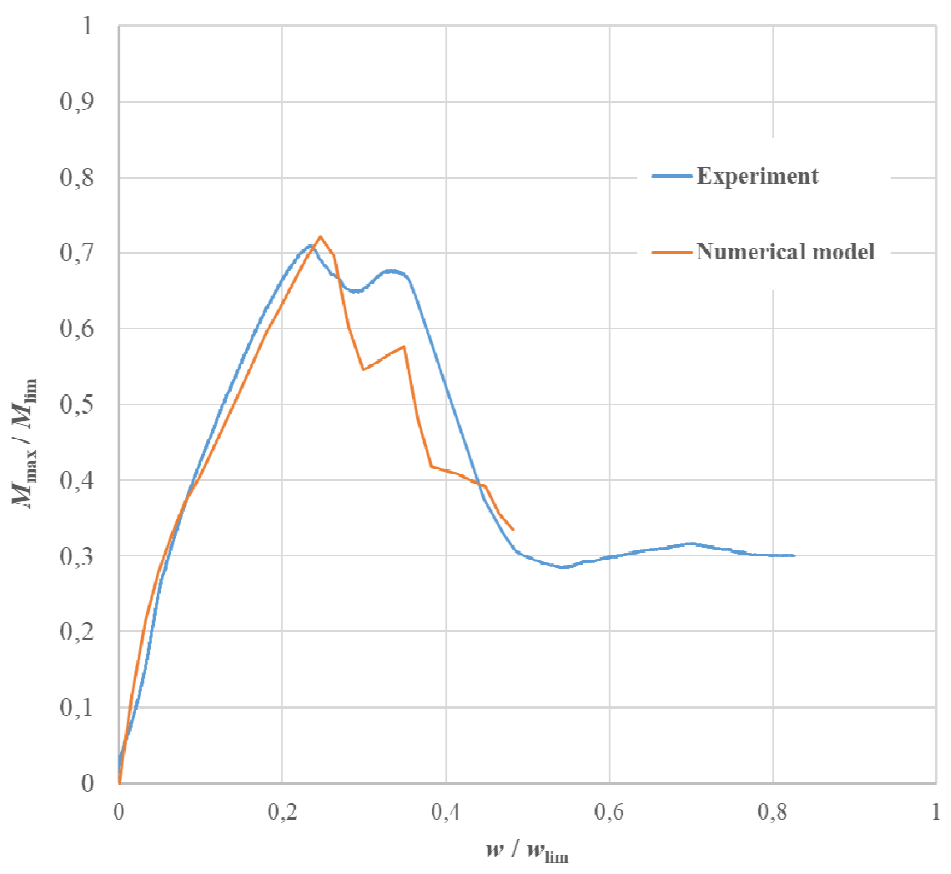

Fig. 16. Results of three-point load test and non-linear numerical analysis

It shows the dependence between the bending moment and the moment-related deformation on the ultimate strength and the specified limit deflection 1/150 of the span. The two curves in the charts that show a high degree of correlation show the typical phases of loading of concrete elements. This is the area before the occurrence and development of cracks and beam collapse. The beam collapsed due to shear. The calculation model in non-linear analysis initially has a higher stiffness than the experiment. The resulting maximum load in the experiment is $40.8 \mathrm{kN}$, and numerical model has $41.5 \mathrm{kN}$, differing by only to $0.7 \mathrm{kN}$ from the maximum load in the load test.

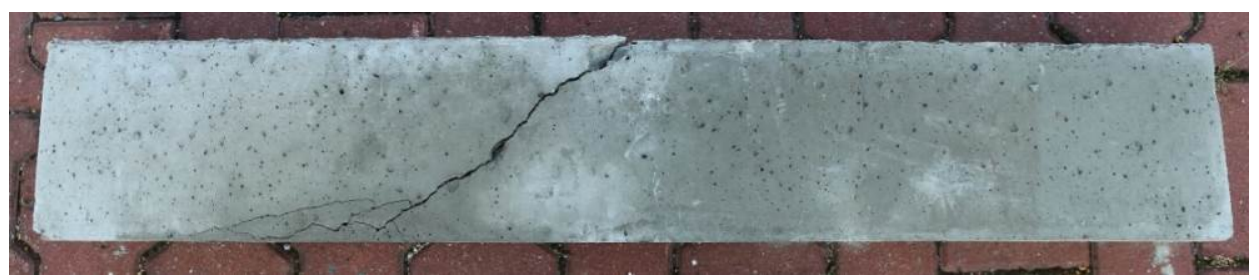

Fig. 17. Beam after the test-shear crack

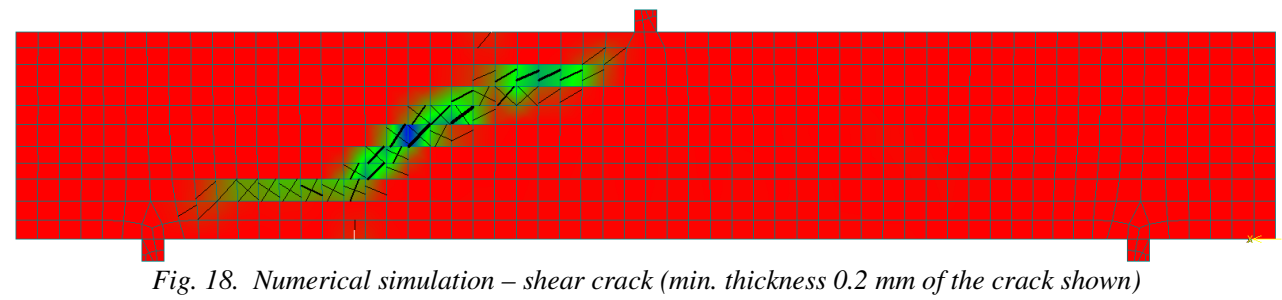


The same mechanism for the development of the shear crack in the experiment and the numerical model is shown in Figs. 17 and 18. The resulting fracture energy used is $52.1 \mathrm{~N} / \mathrm{m}$. The material parameters of the concrete for non-linear analysis are summarised in Tab. 3 .

\begin{tabular}{cc}
\multicolumn{2}{c}{ Tab. 3. Material model of concrete } \\
\hline Material properties & Values \\
\hline Modulus of elasticity & $18.5 \mathrm{GPa}$ \\
Poisson ratio & 0.2 \\
Compressive strength of the cylinder & $24.66 \mathrm{MPa}$ \\
Tension strength & $2.12 \mathrm{MPa}$ \\
Aggregate size max. & $16 \mathrm{~mm}$ \\
Crack & fixed \\
Critical com. displacement & $0.0005 \mathrm{~m}$ \\
Fracture energy & $52.1 \mathrm{~N} / \mathrm{m}$ \\
\hline
\end{tabular}

\section{Experimental loading test of the concrete slab}

As mentioned above, the main parts of the experimental program were the load test of the concrete slab on the subsoil. The basic dimension of the concrete slab was 2000 x $2000 \mathrm{~mm}$. The slab thickness was $150 \mathrm{~mm}$. The purpose of the concrete slab test was to determine the maximum load and deformation and also the method of structure collapse. Vertical deformation measurements were performed by a set of 24 sensors. Furthermore, the force applied to the centre of the slab through the hydraulic piston was recorded. An acoustic emission measurement was used to identify the occurrence of cracks at the lower surface of the concrete slab. For the measurement of acoustic emission, use was made of 8 sensors which divided the slab into eight sectors. The loading surface area was $400 \times 400 \mathrm{~mm}$. The process of loading of the concrete slab was in steps. The resulting charts of cross-sections of vertical deformations are shown in Figs. 19 to 22. The Load was applied in steps of 35 $\mathrm{kN}$. The resulting record of the acoustic sensors is shown in Fig. 23. The very low acoustic emission levels in the middle of the slab are already identified before for load-interval 35 between $70 \mathrm{kN}$. The main AE was in the range of $70-105 \mathrm{kN}$ for sensors 2, 3, 5, 6 and 7. The first visible cracks in concrete at the edges of the slab are around the load $90-105 \mathrm{kN}$, the third cycle's end. There is after also a gradual development of cracks to the edges of the slab. The cracks can be well localised, they have a perpendicular direction and gradually open. They are also shown in Fig. 24. After cracks occur, there is also another phenomenon - the edges of the slab are lifted, as shown in Fig. 25. The max peak of acoustic emissions is recorded at intervals at the beginning between 105 and $140 \mathrm{kN}$ load, fourth load step. At the load of $140 \mathrm{kN}$, the test is terminated. The pressure in the load of hydraulics cylinder rapidly decreases, and the slab is visibly divided into smaller segments, and the pushing of the slab of the segment has become into the subsoil. Also, the slab is pushed into the subsoil/ground gradually. It is evident from the vertical deformation sensors that the maximum deflection in the middle of the slab, as expected. The resulting edge lifting values are affected by crack location. There is also a typical phenomenon that the edges of the slab are lifted. It is particularly noticeable that the slab in the area between the sensors 2 and 6 is lifted.

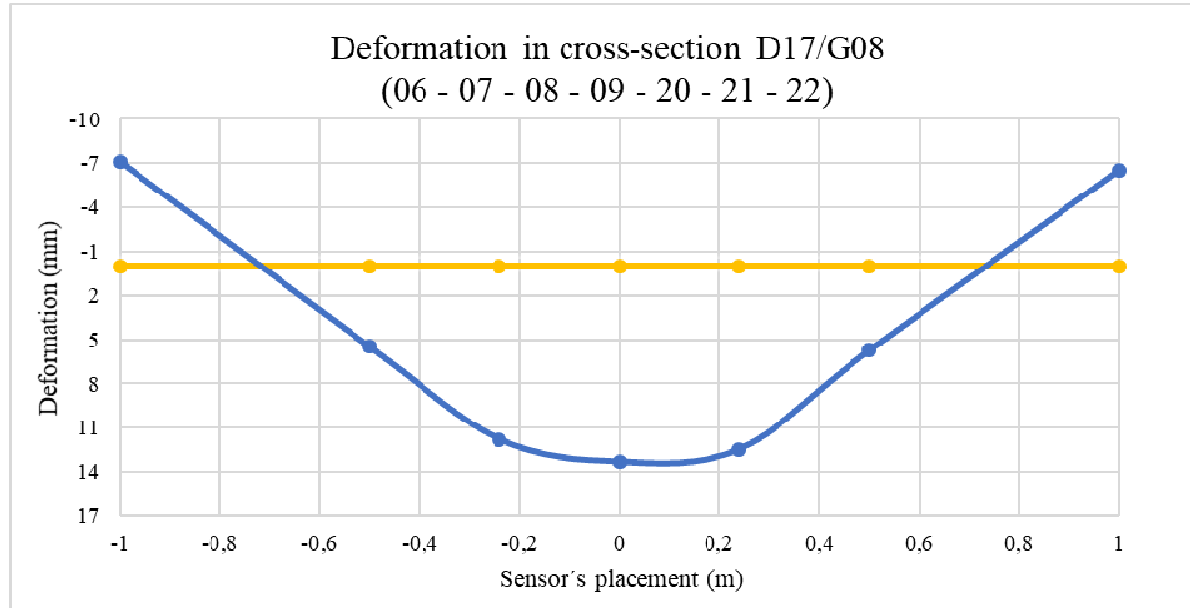

Fig. 19. Deformation [mm] (sensors 06-22) 


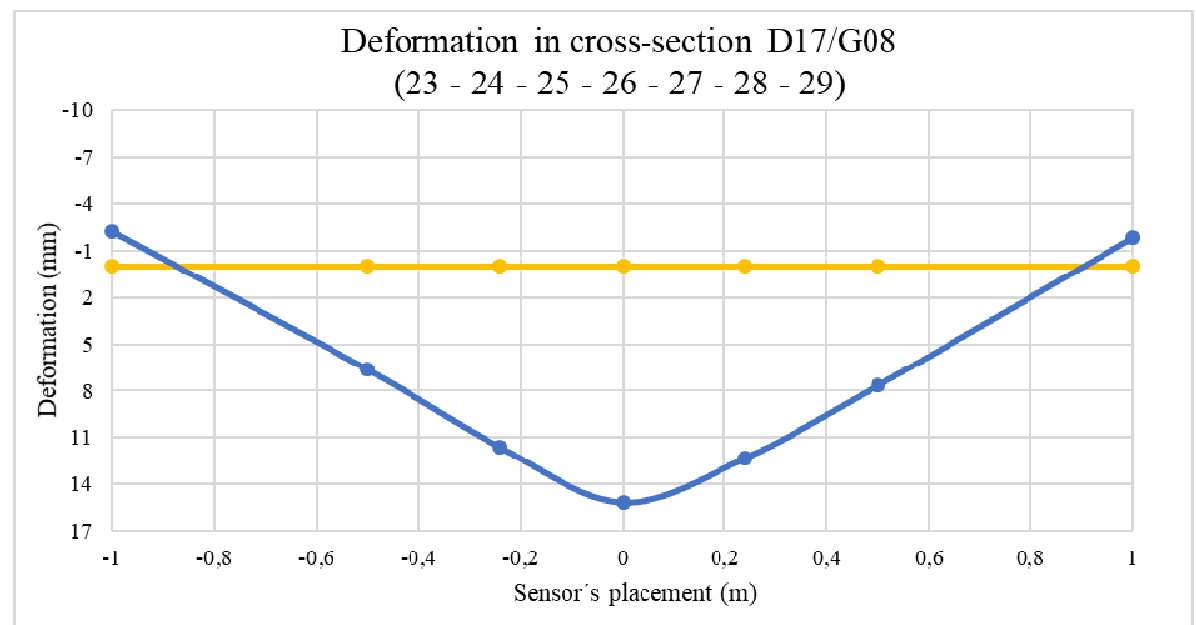

Fig. 20. Deformation [mm] (sensors 23-29)

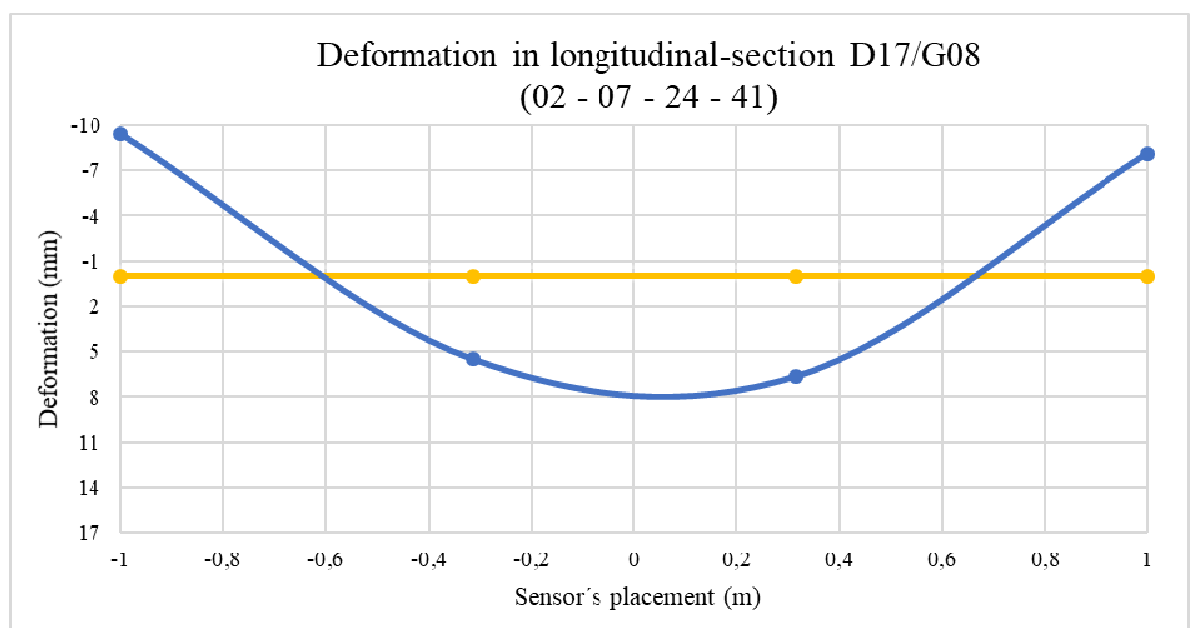

Fig. 21. Deformation [mm] (sensors 02-41)

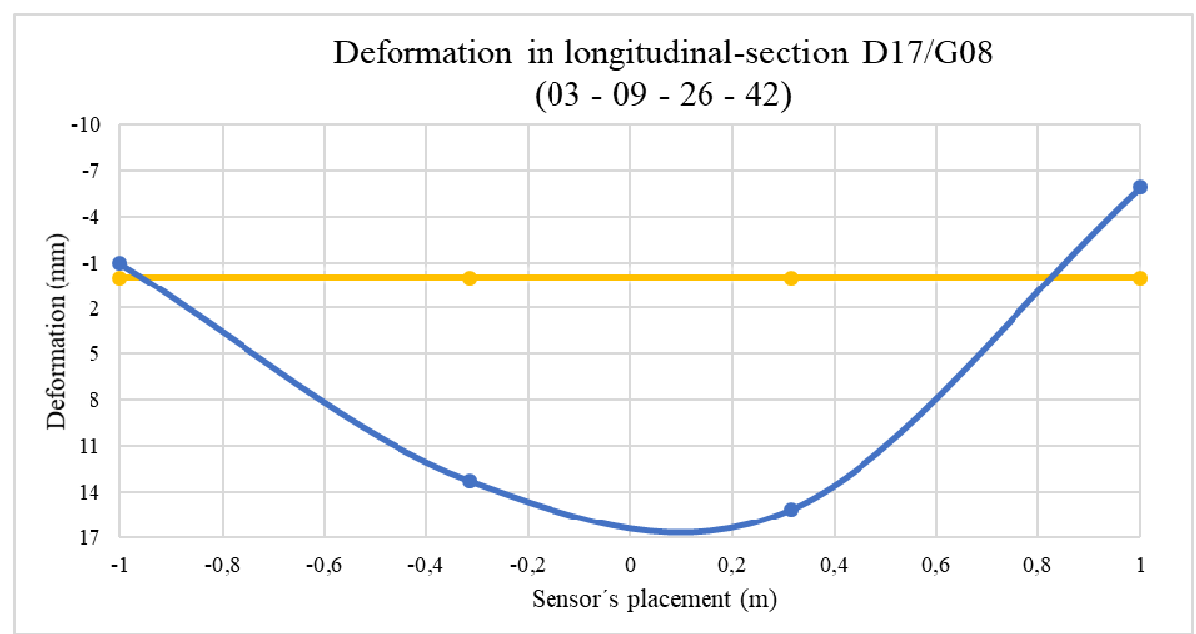

Fig. 22. Deformation [mm] (sensors 03-42)

The resulting maximum vertical deformation is typically $14-17 \mathrm{~mm}$ according to the sensors. When the maximum load is reached, the fragmented slab is pushed into the subsoil. The resulting cracks are well visible in Fig. 26. The measurements of AE results are processed in graphical form in Fig. 23 for each sensor.

The longitudinal sections of the slab in Fig. 21 and Fig. 22 show the asymmetrical deformations of the slab, which occurred due to the asymmetrical formation of cracks during the load test. The more significant formation of cracks occurred mainly on one side of the slab, as can be seen from Fig. 26. For this reason, there was also a different behaviour of the opposite sides of the slab, different lifting the corners of the slab, as shown in Fig. 22. 


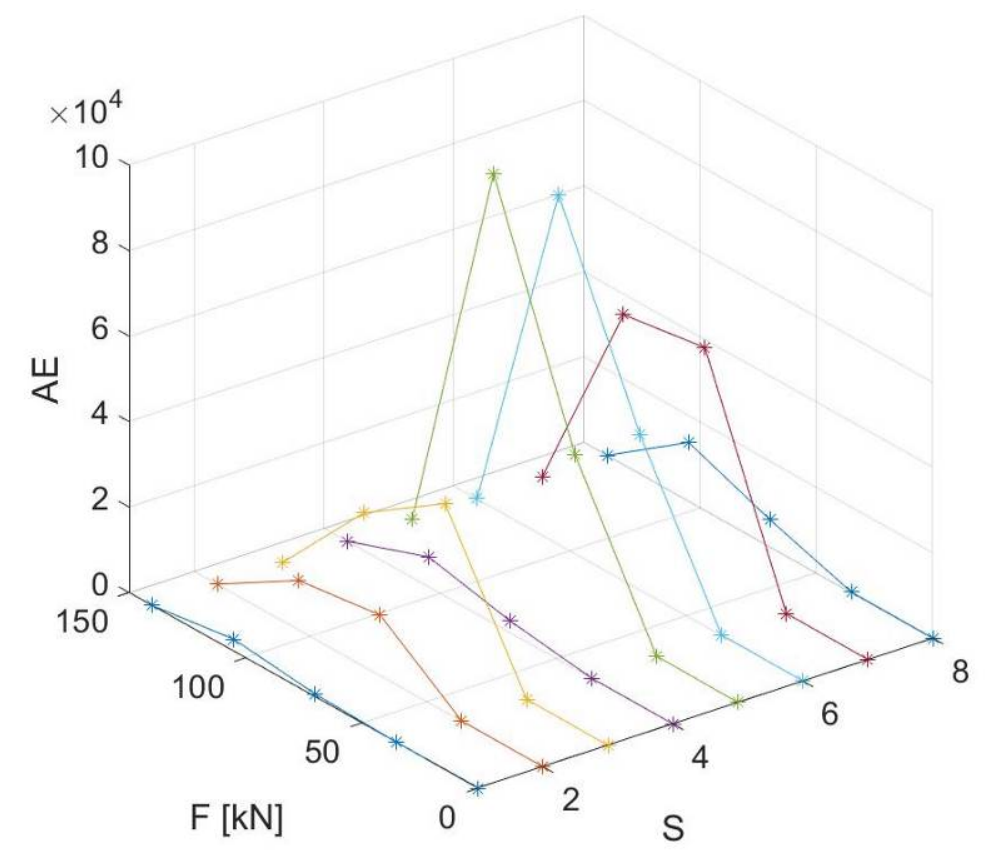

Fig. 23. Measurement of acoustic emission: $A E$

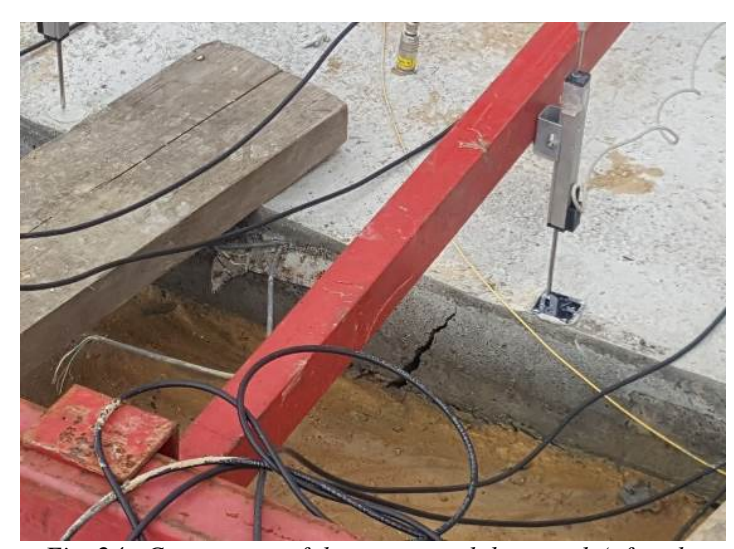

Fig. 24. Center area of the concrete slab-crack (after the test)

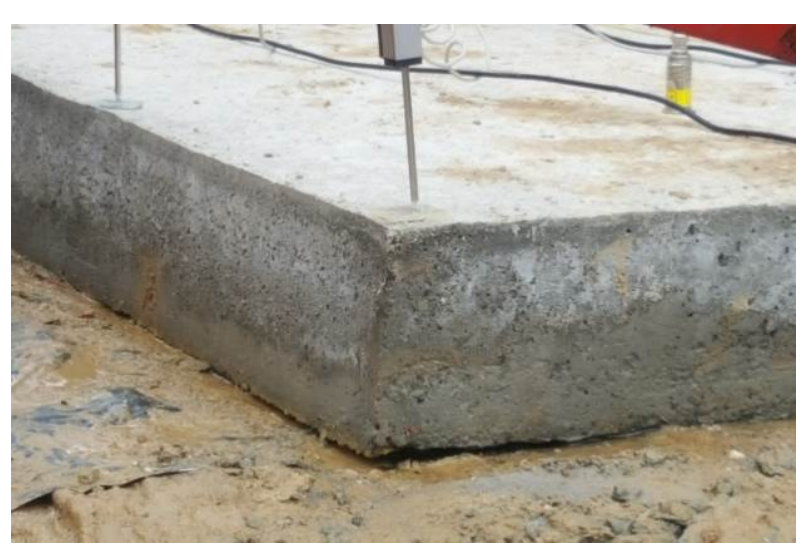

Fig. 25. Edge area of Concrete slab (after the test)

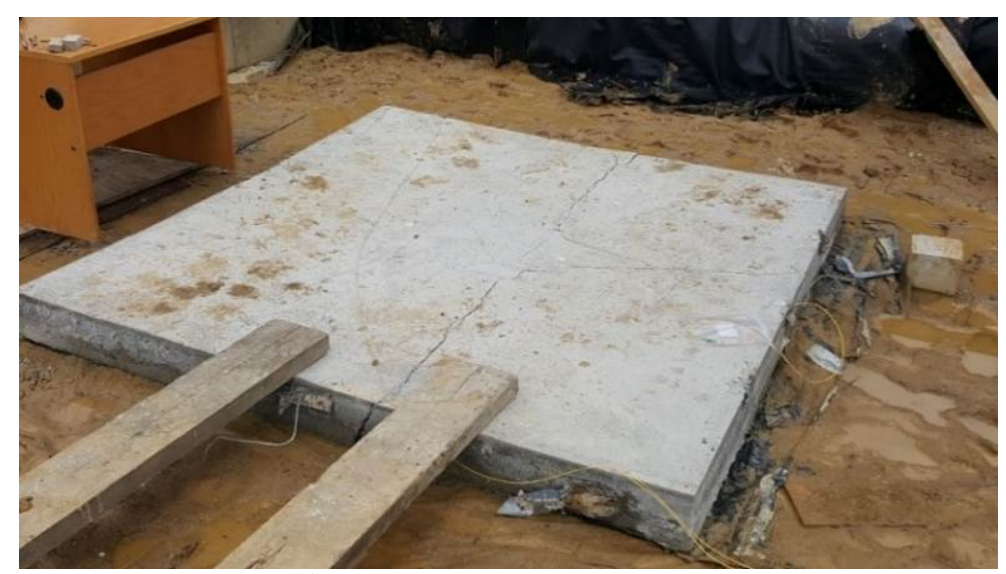

Fig. 26. Concrete slab witch crack - after the test 


\section{Numerical modelling of slab and subsoil}

Using a comprehensive set of input material parameters, numerical modelling of the load test of the concrete slab on the subsoil was performed. The aim of numerical modelling was primarily to determine the slab's overall load capacity and the manner of its disruption. With regard to the nature of the task, 3D computational models were used, see Fig 27. The selection of the constituent concrete model was based on the non-linear analysis of a small structural element and laboratory tests, making use of the fracture-plastic (3D NonLinear Cementitious 2) model in the ATENA system (Cervenka and Papanikolaou, 2008), (Cervenka, Jendele and Cervenka, 2016). The model is in compliance with Model Code 2010 (Model Code 2010 - Final draft). The 3D calculation model included a concrete slab, a steel load plate and subsoil. The model subsoil depth was $2 \mathrm{~m}$. The finite element mesh has a regular shape shown in Fig. 28. The ground plan dimension of the model was $6 \mathrm{x}$ $6 \mathrm{~m}$. In the case of the subsoil, the modulus of elasticity $E=1.5 \mathrm{MPa}$ was used, which was set at the lowest measurable value, which was not achieved for the test conditions in a specialised geotechnical test. A contact interface is modelled between the slab and the subsoil. The task was solved using the arc length method. The load was applied by force in $10 \mathrm{kN}$ steps. The visualisation of the 3D calculation model is shown in Figs. 27 and 28.

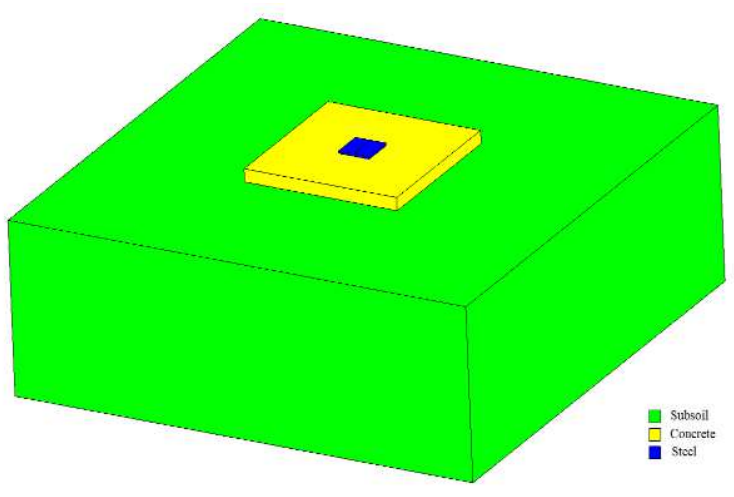

Fig. 27. 3D Calculation model

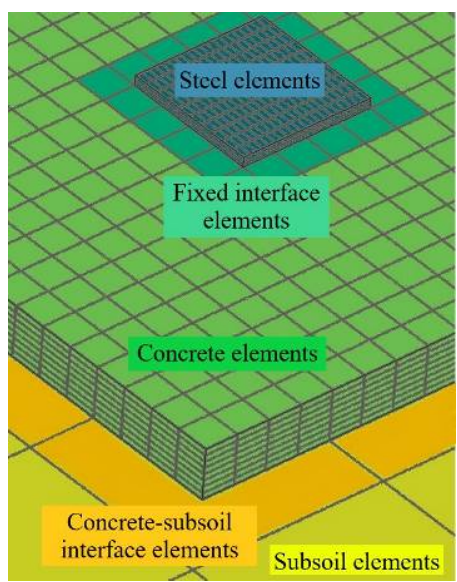

Fig. 28. Mesh finite elements - concrete

\section{Results and Discussions}

The presented research article concerning the interaction between the subsoil and concrete slab under extreme groundwater level conditions has found that, according to the logical assumption, the slab's load capacity decreases rapidly, especially the collapse of the structure is significantly accelerated compared to subsoil with higher load capacity. The examination of the problem requires detailed knowledge of laboratory tests. The proposed laboratory program provided all the important material parameters of concrete, which were also supplemented by including fracture-mechanical parameters using the small structure element.

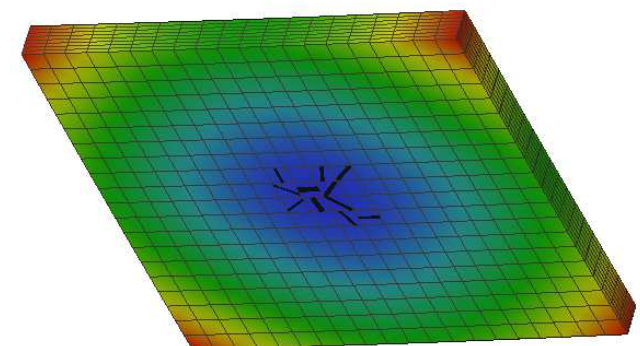

Fig. 29. Concrete slab with crack ( $78 \mathrm{kN}$, microcrack)

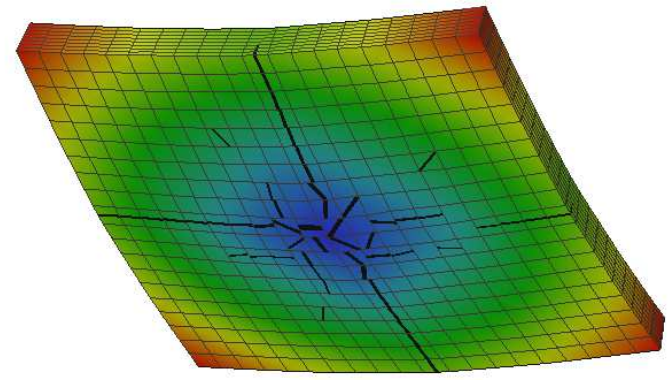

Fig. 30. Concrete slab with crack $(107.1 \mathrm{kN}$, crack min. $0.001 \mathrm{~m})$

The importance of verifying mechanical properties has been demonstrated, especially in the modulus of elasticity, which was significantly smaller than the recommendation in the Model Code 2010 (Model Code 2010 - Final draft). On the other hand, laboratory strength tests have shown that tensile strength variation was similar for all types. The differences were small.

This also points to good homogeneity and concrete processing. However, the resulting tensile strength of $2.12 \mathrm{MPa}$ is significantly lower than the compressive strength of $24.66 \mathrm{MPa}$. The actual course of the load test 
showed that the effect of the elevated groundwater level is significant. The slab was being pushed into the subsoil. The outcome of measurement itself is also influenced by the testing method and the experiment. The total slab load capacity was the interval from 105 to $140 \mathrm{kN}$. With regard to acoustic emission results, the result was refined to a range of $105-120 \mathrm{kN}$. For non-linear analysis, the result of the test was $107.1 \mathrm{kN}$. The mechanism of plate disruption in the experiment and the calculation model was very similar. For illustration, Fig. 29 shows the development of microcracks in concrete for $78 \mathrm{kN}$ calculated load; cracks have already affect bending stiffness. Fig. 30 shows cracks in concrete for computational results with maximal load 107.1 kN.

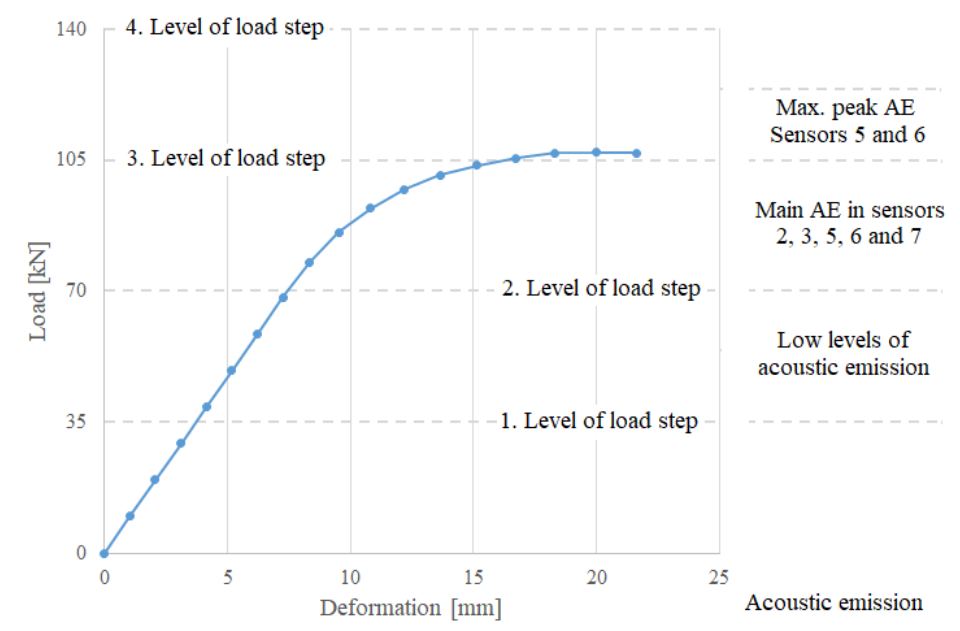

Fig. 31. Non-linear analysis - LD diagram and level of acoustic emission

Once the tensile strength of the concrete is reached in the middle of the bottom side of the slab, cracks and lifting of the edges of the slab occur. The cracks' actual propagation was from the centre to the edges of the slab, in one to two dominant vertical cracks. The crack development itself progressed very quickly, and the test was then terminated. The concrete slab broke into smaller parts, which were then pushed into the ground. The actual initialisation of the cracks and their propagation was detected using acoustic emissions. A more detailed study found that by comparing the sensors, it is possible to identify the sector where the disruption - crack occurs. The first very low acoustic emissions began to occur under a load of 35-70 kN and main acoustic emissions for 70$105 \mathrm{kN}$ loads. These acoustic emissions can be bevor considered as cracks. This is also in line with the nonlinear calculation and the load/AE - displacement diagram in Fig. 31. The mechanism of plate disruption in the experiment and the calculation model was very similar.

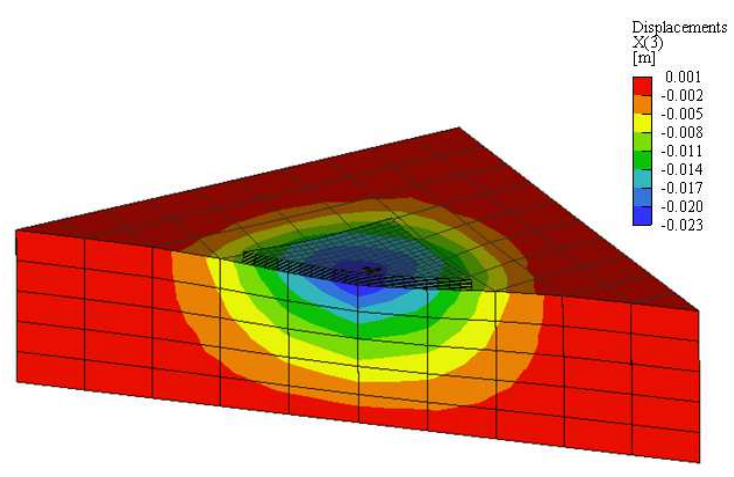

Fig. 32. Deformation $\mathrm{z}[\mathrm{m}]$ and crack of concrete $(107.1 \mathrm{kN})$

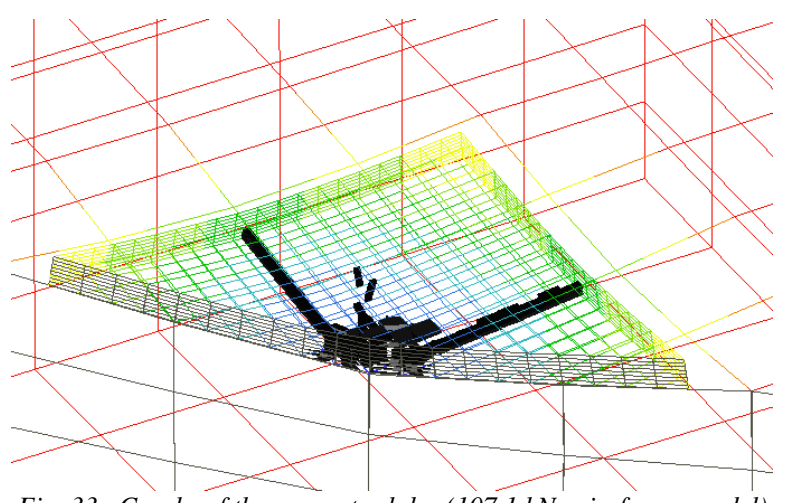

Fig. 33. Cracks of the concrete slab-(107.1 kN, wireframe model $)$

In particular, there are significant cracks in the middle of the slab and at the place of the (loading) steel plate. In the course of further loading, the load is reduced, and diagonal cracks develop. This is also well evident in an experimental photo. The model's overall deformation pattern is shown in Fig. 32 and in the detail of the concrete slab in Fig. 33. The match in the calculated deformations can be considered good for the overall calculation model. The greatest differences occurred, especially in the vicinity of the load plate, where large concentrations of stress in concrete and subsoil also occurred. 


\section{Conclusion}

The article presents the complete results of the task concerning the interaction between a concrete slab and subsoil. The numerical modelling using the finite element method and non-linear analysis very well simulated the actual behaviour of the slab and subsoil. The experiment itself - a load test of interaction between the slab and subsoil, confirmed the groundwater level's significant influence. The overall load capacity decreases significantly, and in particular, it is important that the mechanism of disruption and collapse is very rapid. The models described the manner of the occurrence and propagation of cracks well. The load capacity of the slab was determined mainly by concrete and its mechanical properties. The scope of laboratory tests and the chosen evaluation methods made it possible to adequately describe input parameters of concrete for subsequent numerical modelling using the finite element method and non-linear analysis. The use of acoustic emission facilitated the validation of plate behaviour during the experiment and non-linear calculations. Its usability was already confirmed by the initial occurrence of cracks, which was also in line with numerical models. This crack detection with regard to the experiment's configuration cannot simply be verified visually, although it is very important for subsequent numerical modelling taking into account actual behaviour. The most incoherent findings are that after the occurrence of cracks, there was a very rapid breakage of the slab into smaller parts and collapse. This indicates the preference for the choice of other design or material solutions. In particular, the use of fibre reinforced concrete could be considered advantageous. The authors will further focus on this area in the future.

\section{References}

Aboutalebi, M., Alani, A., Rizzuto, J. and Beckett, D. (2014). Structural behaviour and deformation patterns in loaded plain concrete ground-supported slabs. Structural Concrete, 15(1), pp. 81-93. DOI:10.1002/suco.201300043.

Brozovsky, J., Konecny, P., Mynarz, M., Sucharda, O. (2009). Comparison of alternatives for remodelling of laboratory tests of concrete. Proceedings of the 12th International Conference on Civil, Structural and Environmental Engineering Computing.

Cajka, R., Labudkova, J. and Mynarcik, P. (2016). Numerical solution of soil - foundation interaction and comparison of results with experimental measurements. International Journal of GEOMATE, 11(1), pp. 2116-2122.

Cajka, R., Krivy, V. and Sekanina, D. (2011). Design and Development of a Testing Device for Experimental Measurements of Foundation Slabs on the Subsoil. Transactions of the VSB - Technical University of Ostrava, Civil Engineering Series, 11 (1), pp. 1-5. DOI: 10.2478/v10160-011-0002-2.

Cajka, R. (2013). Accuracy of Stress Analysis Using Numerical Integration of Elastic Half-Space. Applied Mechanics and Materials, 300-301, 9 pages. DOI 10.4028/www.scientific.net/AMM.300-301.1127.

Cajka, R., Marcalikova, Z., Neuwirthova, Z., Mynarcik, P. (2019). Testing of FRC foundation slab under eccentric load. Proceedings of the fib Symposium 2019: Concrete - Innovations in Materials, Design and Structures, pp. 380-386.

Cajka, R., Marcalikova, Z., Kozielova, M., Mateckova, P., Sucharda, O. (2020). Experiments on Fiber Concrete Foundation Slabs in Interaction with the Subsoil. Sustainability, 12, 3939. DOI:10.3390/su12093939

Ceylanoğlu, A., Gül, Y. (2016) Vibration measurements for the prediction of ground bearing capacity. Acta Montanistica Slovaca, 21 (2), pp. 113-119.

Cervenka, J. and Papanikolaou, V. K. (2008). Three dimensional combined fracture-plastic material model for concrete, International Journal of Plasticity, 24 (12), pp. 2192-2220.

Cervenka, V., Jendele, L. and Cervenka, J. (2016). ATENA Program documentation - Part 1: Theory. Cervenka Consulting. Prague.

ČSN EN 1992-1-1 (2006), Eurocode 2: Design of concrete structures - Part 1-1: General rules and rules for buildings.

ČSN ISO 1920-4 Testing of concrete-Part 4: Strength of hardened concrete.

ČSN ISO 1920-10 Testing of concrete-Part 10: Determination of static modulus of elasticity in compression.

EN 1997-1 (2004) (English): Eurocode 7: Geotechnical design-Part 1: General rules [Authority: The European Union Per Regulation 305/2011, Directive 98/34/EC, Directive 2004/18/EC]

Grosse, Ch. U. and Ohtsu, M. (2008). Acoustic emission testing. Springer, Berlin, ISBN 978-3-540-69895-1.

Halvonik, R. and Fillo, J. (2013). The Maximum Punching Shear Resistance of Flat Slabs. Procedia Engineering, 65, pp. 376-381, ISSN $1877-7058$.

Hegger, J., Ricker, M., Ulke, B. and Ziegler M. (2006). Investigations on the punching behaviour of reinforced

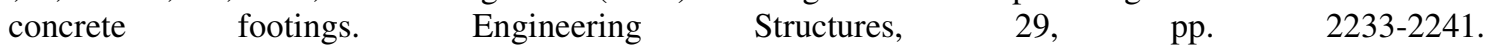
DOI:doi.org/10.1016/j.engstruct.2006.11.012 
Hegger, J., Sherif, G. A. and Ricker M. (2006). Experimental Investigations on Punching Behaviour of Reinforced Concrete Footings. ACI Structural Journal, pp. 604-613.

Hoang, L.C. and Pop, A. (2016). Punching shear capacity of reinforced concrete slabs with headed shear studs. Magazine of Concrete, 68, 9 pages. DOI 10.1680/macr.15.00033.

Ibrahim, M. and Metwally, I. M. (2014). Three-dimensional finite element analysis of reinforced concrete slabs strengthened with epoxy-bonded steel plates. Advances in Concrete Construction, 2(2), pp. 91-108. DOI:10.12989/acc.2014.2.2.091.

Invernizzi; S., Lacidogna, G. and Carpinteri, A. (2016). Numerical Models for the Assessment of Historical Masonry Structures and Materials, Monitored by Acoustic Emission. Appl. Sci., 6(4), 102. DOI:10.3390/app6040102.

ISO 1920-4:2005 Testing of concrete -- Part 4: Strength of hardened concrete.

Kueres, D., Ricker, M. and Hegger, J. (2018). Improved Shear Reinforcement for Footings - Maximum Punching Strength. ACI Structural Journal, 115, 13 pages, DOI: 10.14359/51702374.

Kaláb, Z., Hrubešová, E. (2015) Evaluation of seismic effect of traffic-induced vibrations. Acta Montanistica Slovaca, 20 (1), pp. 33-37.

Kaláb, Z., Štemon, P. (2017). Influence of seismic events on shallow geotechnical structures. Acta Montanistica Slovaca, 22 (4), pp. 412-421.

Kralik, J. and Jendzelovsky, N. (1994). Contact Problem of Reinforced Concrete Girder and Non-Linear Winkler Foundations, Geomechanics 93, Ostrava, pp. 233-236.

Kolar, V. and Nemec, I. (1989). Modelling of Soil-structure Interaction. Elsevier, New York, USA. ISBN 04449-8859-9.

Kueres, D., Ricker, M. and Hegger, J. (2017). Improved Shear Reinforcement for Footings— Punching Strength inside Shear-Reinforced Zone. Aci Structural Journal, 114 (6), pp. 1445-1456. DOI: 10.14359/51689499.

Lacidogna, G., Piana, G. and Carpinteri, A. (2017). Acoustic Emission and Modal Frequency Variation in Concrete Specimens under Four-Point Bending, Appl. Sci., 7(4), 339. DOI:10.3390/app7040339.

Marcalikova, Z., Cajka, R., Bilek, V., Bujdos, D., Sucharda, O. (2020). Determination of Mechanical Characteristics for Fiber-Reinforced Concrete with Straight and Hooked Fibers. Crystals, 10, 545. DOI:10.3390/cryst10060545

Model Code 2010 - Final draft, fib, Bulletin no. 65 and 66, 1-2. 2012.

Nosov, V. V. (2016). On the principles of optimising the technologies of acoustic-emission strength control of industrial objects. Russian Journal of Nondestructive Testing, 52(7), pp. 386-399.

Pazdera, L. and Topolar, L. (2014). Application acoustic emission method during concrete frost resistance, Russian Journal of Nondestructive Testing, 50, 2, pp. 127-131. DOI: 10.1134/S1061830914020065.

Pazdera, L., Cajka, R., Topolář, L., Mateckova, P., Bilek, V., Sucharda, O. (2019). Measurement and utilisation of acoustic emission for the analysis and monitoring of concrete slabs on the subsoil. Periodica Polytechnica Civil Engineering, 63 (2), pp. 608-620. DOI: 10.3311/PPci.12695

Pollock, A. A. (1988). Practical guide to acoustic emission testing. Physical Acoustic Corporation - Princeton, New Jersey.

Ricker, M. and Siburg, C. (2016). Punching shear strength of flat slabs - critical review of Eurocode 2 and fib Model Code 2010 design provisions. Structural Concrete, 17(3), pp. 457-468.

Sagasta, F., Amadeo Benavent-Climent, Roldan, A. and Gallego, A. (2016). Correlation of Plastic Strain Energy and Acoustic Emission Energy in Reinforced Concrete Structures. Appl. Sci., 6(3), 84. DOI:10.3390/app6030084.

Siburg, C. and Hegger, J. (2014). Experimental investigations on the punching behaviour of reinforced concrete footings with structural dimensions, Structural Concrete, 15(3). DOI: 10.1002/suco.201300083.

Sokol, M., Venglár, M., Lamperová, K., Márföldi, M. (2020) Performance Assessment of a Renovated Precast Concrete Bridge Using Static and Dynamic Tests. Appl. Sci., 10, 5904.

Sucharda, O. and Konecny, P. (2018). Recommendation for the modelling of 3D non-linear analysis of RC beam tests. Computers and Concrete, 21, 10 pages. DOI:10.12989/cac.2018.21.1.011.

Sucharda, O., Smirakova, M., Vaskova, J., Mateckova, P., Kubosek, J. and Cajka, R. (2018). Punching Shear Failure of Concrete Ground Supported Slab, International Journal of Concrete Structures and Materials, 12 (1), art. no. 36 .

Sucharda, O. (2020). Identification of Fracture Mechanic Properties of Concrete and Analysis of Shear Capacity of Reinforced Concrete Beams without Transverse Reinforcement. Materials 2020, 13, 2788. DOI:10.3390/ma13122788

Sucharda, O., Mateckova, P., Bilek, V. (2020). Non-linear analysis of an rc beam without shear reinforcement with a sensitivity study of the material properties of concrete. Slovak Journal of Civil Engineering, 28 (1), pp. 33-43. DOI: 10.2478/sjce-2020-0005

Tomasovicova, D. and Jendzelovsky, N. (2017). Stiffness Analysis of the Subsoil under Industrial Floor, Procedia Engineering, 190, pp. 365-370. DOI: 10.1016/j.proeng.2017.05.350. 
Topolar, L., Pazdera, L., Kucharczykova, B., Smutny, J. and Mikulasek, K. (2017). Using Acoustic Emission Methods to Monitor Cement Composites during Setting and Hardening, Appl. Sci., 7(5), 451. DOI:10.3390/app7050451.

Zienkiewicz, O. C. (1971). The Finite Element Method in Engineering Science. London: McGraw-Hill. 